\title{
PENGAJARAN KOMPETENSI BAHASA INGGRIS UNTUK SEKOLAH MENENGAH KEJURUAN
}

\author{
Drs. Putut Handoko, M.Pd \\ Drs. Sanhari Parawiradiredja, M.Si \\ Budi Santoso, ST., MT \\ Universitas Dr. Soetomo Surabaya \\ E-mail: putut.handoko@unitomo.ac.id, sanhari.prawiradiredja@unitomo.ac.id,santosobudi.id@gmail.com
}

\begin{abstract}
ABSTRAK
Pengabdian masyarakat ini dilakukan untuk mengembangkan kompetensi bahasa siswa di kalangan siswa Sekolah Menengah Kejuruan. Siswa yang dipilih adalah siswa kelas XII dengan pertimbangan mereka akan menyelesaikan proses belajar di sekolah dan terjun ke masyarakat dengan memanfaatkan ketrampilan yang dimiliki. Mitra pengabdian pada masyarakat adalah Siswa Kelas XII SMK Mahardhika Surabaya. Dari analisis situasi yang dilakukan nampak bahwa permasalahan yang dihadapi mitra adalah siswa kelas adalah kurangnya motivasi belajar karena anggapan dasar bahwa Bahasa Inggris adalah mata pelajaran yang sulit. Dari pretest yang dilakukan ada beberapa materi dasar yang sulit dipahami khususnya reading, kurang mengerti topic, main idea, dan menjawab WH Question serta kurang fokusnya siswa dalam mengikuti proses pembelajaran. Pengajaran menggunakan pendekatan komunikasi persuasif motivasional, diadakan tes awal, pengajaran topic, main idea, dan WH Question dengan pengayaan materi. Setelah proses treatment tersebut diadakan tes evaluasi (post test) yang menampakkan hasil bahwa siswa mulai termotivasi belajar Bahasa Inggris, fokus dan mandiri dengan hasil tes rata-rata nilai bagus. Kontribusi dan manfaat yang diperoleh khalayak sasaran adalah motivasi belajar Reading, fokus dan mandiri dalam belajar bahasa inggris.
\end{abstract}

Kata kunci: Pembelajaran Bahasa, komunikasi persuasif, motivasional, treatment pengabdian

\section{PENDAHULUAN}

\section{Analisis Situasi}

Sekolah Menengah Kejuruan (SMK) merupakan sekolah menengah yang mempersiapkan siswa untuk dapat langsung bekerja dengan kemampuan vokasional yang dimilikinya. Pendidikan kejuruan seperti SMK merupakan bagian dari sistem pendidikan yang mempersiapkan seseorang agar lebih mampu bekerja pada satu kelompok pekerjaan atau satu bidang pekerjaan daripada bidang bidang pekerjaan lain (www.psmk. kemdikbud.go.id) Kompetensi yang diajarkan kepada siswa tentunya berbasis kurikulum yang berlaku secara nasional. Setelah mereka menyelesaikan tahapan pembelajaran mereka akan memasuki dunia kerja sesuai dengan bidangnya. Mereka akan bersaing dengan calon pekerja lain dengan bidang vokasi yang sama. Oleh karena itu, diperlukan alternatif-alternatif lain untuk memperkuat ketrampilan (skill) mereka disamping kapabilitas yang diajarkan melalui kurikulum yang berlaku. Salah satu skill yang diperlukan dalam menghadapi pasar kerja adalah kemampuan bahasa Inggris. Kemampuan bahasa Inggris ini penting karena menjadi dasar interaksional dalam memasuki dunia kerja.

SMK Mamardhika Surabaya adalah sekolah kejuruan yang terakreditasi A dan bersertifikat ISO 9001:2008. SMK Mahardhika Surabaya mempunyai dua jurusan yaitu (a) Akuntansi dan b) Multi Media. Kompetensi yang diajarkan kepada siswa tentunya berbasis kurikulum yang berlaku.
Kurikulum 2013 revisi terbaru memasukkan mata pelajaran Bahasa Inggris sebagai mata pelajaran wajib, yang harus ditempuh oleh siswa. Buku Bahasa Inggris yang dipakai di SMK Mahardhika kelas XII adalah Buku Bahasa Inggris XII yang fokus pada Reading Comprehension. Anggapan bahwa Buku Bahasa Inggris XII sulit, menjadi permasalahan baik bagi guru Bahasa Inggris maupun siswa. Pelajaran Bahasa Inggris di SMA dan SMK masih menjadi pelajaran yang sulit bagi siswa. Faktor siswa SMK, Buku bahasa Inggris yang dipakai, sarana ruang kelas yang belum dianggap memadai, dan keterbatasan waktu praktik dirasakan sebagai hambatan untuk menguatkan kompetensi siswa dalam pelajaran bahasa Inggris. Oleh karenanya dibutuhkan alternatif pengembangan kompetensi bahasa Inggris siswa. Pengabdian kepada masyarakat yang akan dilakukan akan dilaksanakan untuk memenuhi kebutuhan ini. Dengan menekankan pada implementasi dan praktek dan pengayaan materi diharapkan peningkatan kompetensi akan tumbuh dan diharapkan secara personal siswa akan mengembangkan kompetensi bahasa Inggrisnya.

Team pengabdian masyarakat Universitas Dr. Soetomo akan mengusahakan pengajaran kompetensi Bahasa Inggris dengan metode pengajaran dan penggunaan open source sebagai alternatif penguatan kompetensi siswa dalam belajar bahasa Inggris. Pengajaran kelas klasikal, praktek implementasi langsung dan pendampingan yang akan 
dilakukan oleh team pengabdian Universitas Dr. Soetomo yang bersifat multidisipliner yaitu dari Fakultas Sastra, Fakultas Ilmu Komunikasi dan Fakultas Teknik. Materi yang ditekankan untuk disampaikan adalah materi ekspresi yang bersifat resiprokal. Resiprokal pasif dalam hal ini adalah materi ekspresi dalam pengertian penerimaan yaitu kemampuan yang berkaitan dengan penerimaan pemahaman materi yang bersifat tekstual verbal maupun verbal terucap (lisan). Resiprokal aktif adalah kemampuan mengekspresikan opini ataupun pesan secara aktif. Setelah melalui analisis maka pilihan pengabdian masyArakat difokuskan dalam pengembangan kemampuan penerimaan pesan dalam bentuk tekstual (reading comprehension).

\section{Permasalahan Mitra}

Berdasar analisa situasi tersebut di atas, siswa kelas XIIMM 3 SMK Mahardhika Surabaya menghadapi permasalahan sebagai berikut:

a. Kurangnya motivasi, fokus belajar dan kemandirian belajar untuk meningkatkan kompetensi Bahasa Inggris.

b. Kurangnya pemahaman mengenai materi Reading Comprehension terutama mengenai topic, main idea dan W/H question

c. Kurangnya kelengkapan sarana pembelajaran di kelas seperti perangkat elektronik LCD dan sound system yang mendukung,

\section{METODE PELAKSANAAN}

Tahapan-tahapan pelaksanaan pengabdian kepada masyarakat dijabarkan sebagaimana dalam Gambar 3.1.

Dari gambar 3.1. dapat dijelaskan tahapan kegiatan yang dilaksanakan sebagai berikut:

1. Analisis kebutuhan

a. Tahapan awal ini berupa upaya memahami analisis situasi secara umum yang berkaitan dengan konteks pengajaran kompetensi Bahasa Inggris khususnya Reading Comprehension. Kemudian team pengabdian masyarakat melakukan observasi secara khusus pada permasalahan-permasalahan yang dihadapi mitra dalam hal ini permasalahan yang dihadapi siswa kelas XII MM 3 SMK Mahardhika Surabaya.

b. Team pengabdian masyarakat membuat solusi alternatif untuk menyelesaikan permasalahan mitra dengan Pengajaran kompetensi Bahasa Inggris khususnya Reading comprehension dengan metode pengajaran baik klasik maupun praktek langsung, pemanfaatkan open source instruksional dan pengajaran dengan pendekatan pendampingan.

2. Desain pengabdian masyarakat

Desain pengabdian masyarakat yang dilakukan adalah proses motivasional belajar dalam suasana penyajian formal kelas (Chaer, 2003: 251-253), implementasinya dalam bentuk persuasi yang mengutamakan reward (Hartley, 2010: 234). Untuk menambah efektifitas proses pembelajaran team pengabdian mengembangkan pengayaan materi dari sumber open source di samping buku yang sudah disediakan oleh SMK Surabaya sudah menyiapkan buku panduan yaitu Buku Bahasa Inggris XII, kurikulum 2013 Revisi terbaru. Hal ini dimaksudkan untuk menumbuhkan suasana baru dan menantang yang dapat menumbuhkan kreatifitas belajar (Rakhmat, 2007: 261) sehingga dapat menghilangkan suasana kejenuhan siswa.

3. Proses Implementasi

Proses implementasi meliputi pelatihan dan praktek implementatif. Pelatihan meliputi pemberian motivasi, teori topic dan main idea serta tes awal untuk mengetahui sejauh mana siswa mampu menjawab pertanyaan topic, main idea, dan WH Question/5 WH 1 H. Proses implementatif memfokuskan pada pengajaran Reading comprehension di kelas XII-MM 3 SMK Mahardhika Surabaya.
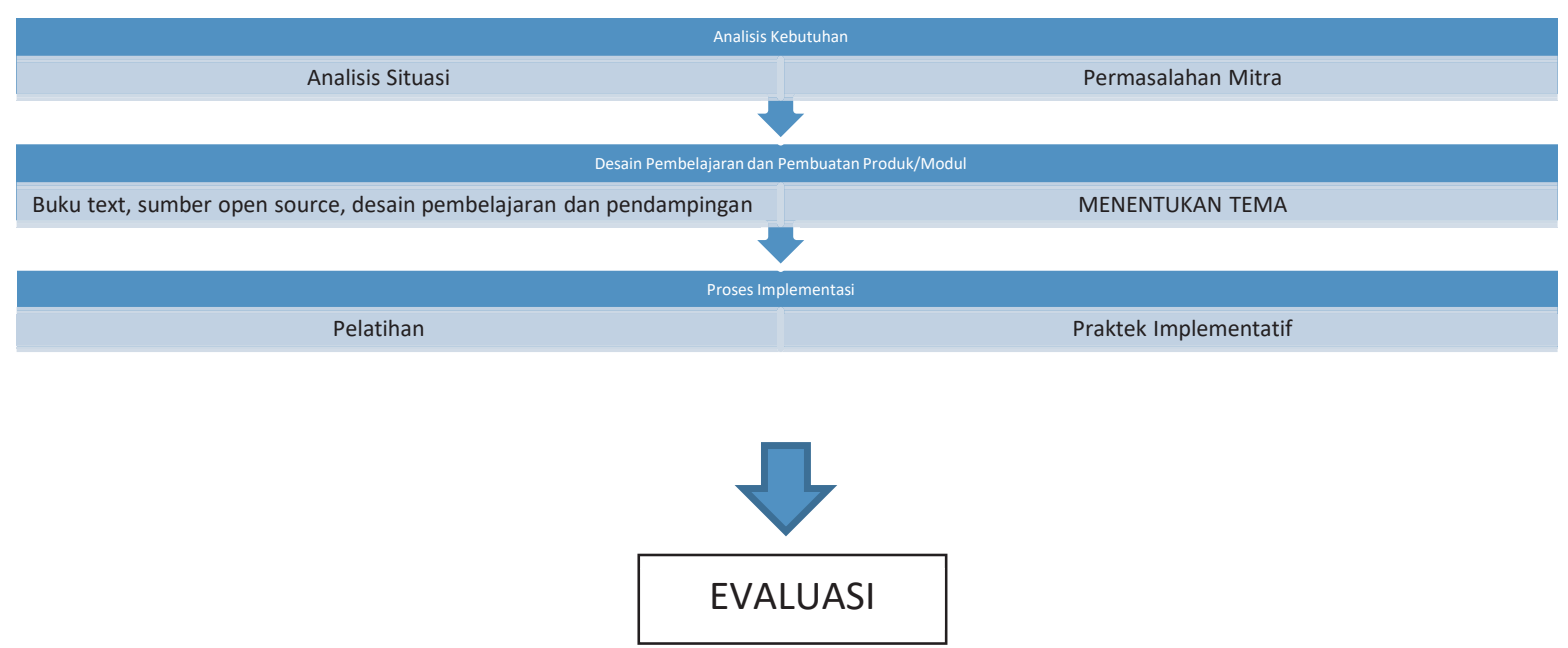

Gambar 3.1. Flowchart Tahapan Kegiatan 
4. Evaluasi

Tes Evaluasi menentukan keberhasilan pengajaran kompetensi Bahasa Inggris. Pada Evaluasi, siswa diberi tes evaluasi untuk mengetahui hasil pengajaran Reading Comprehension baik materi maupun sikap. Tes evaluasi berupa pertanyaan topic, main idea, dan WH Question/5 WH $1 \mathrm{H}$. Yang dimaksud sikap adalah sikap siswa duduk di kursi masing-masing, fokus, dan mengerjakan soal secara mandiri.

\section{HASIL YANG DICAPAI}

Beberapa tahapan dalam pengabdian pada masyarakat berupa pelaksanaan pengajaran 'kompetensi Bahasa Inggris bagi siswa kelas XII di SMK Mahardhika Surabaya adalah analisa situasi, permasalahan mitra, mendisain produk/ buku, menentukan tema, pelatihan, praktek implementatif, dan evaluasi. Tahapan analisis situasi dan permasalahan mitra telah dibahas dalam bab 1. Dalam Bab 5 tentang hasil, tahapan pengabdian masyarakat meliputi mendesain produk/ buku, menentukan tema, pelatihan, praktek implementatif, dan evaluasi.

\section{Hasil}

\section{Mendisain Implementasi Pengabdian}

Buku bahasa Inggris yang dipakai dalam pengajaran Bahasa inggris khususnya Reading comprehension adalah Bahasa Inggris X,II kurikulum 2013 reveisi terbaru. Buku Bahasa Inggris ini diterima dan dipakai di SMK Mahardhika kelas XII pada awal semester gasal 2018/2019. Meskipun secara umum siswa menganggap buku tersebut merupakan buku yang sulit, tim pengabdian masyarakat menggunakannya sebagai acuAn dalam proses pembelajaran, Berbagai sumber open source digunakan untuk mengayakan materi dengan paparan yang lebih simple dan audio visual sehingga lebih variatif.

\section{Menentukan Tema}

Materi awal semester Gasal 2018/2019 untuk Bahasa Inggris adalah Analytical Exposition. Ada lima ciri bahasa analisa exposition yaitu:

1. Menggunakan hubungan proses, kata kerja yang dihubungkan dengan subjek dan kalimat

2. Menggunakan kata penghubung internal, langkah-langkah dalam argumentasi seperti, firstly, secondly, thirdly, etc.

3. Menggunakan kata penghubung sebab akibat, sebab kejadian seperti because, etc

4. Menggunakan kata penghubung kebalikan, menunjukkan lawan kata seperti but, nevertheless, etc

5. Menggunakan tenses/waktu simple present
Pengabdi dalam pelaksanaan pengajaran kompetensi Bahasa Inggris bagi siswa kelas XII di SMK Mahardhika Surabaya menggunakan tema Analisa Exposistion, tetapi tema ini pengabdi bagi dalam sub tema yaitu topic, main idea, dan WH-Question/5 WH, $1 \mathrm{H}$.

\section{Pelatihan}

Pemberian Motivasi

Pelatihan yang berupa pengajaran kompetensi Bahasa Inggris bagi siswa kelas XII di SMK Mahardhika Surabaya diawali dengan memberI solusi permasalahan mitra yaitu kurang motivasi dalam belajar Bahasa Inggris terutama Reading Comprehension. Pengabdi memberikan motivasi belajar bahasa Inggris karena pengabdi percaya bahwa siswa tidak berminat belajar bahasa Inggris, tidak suka Bahasa Inggris, atau menganggap bahasa Inggris sulit, dan bahasa Inggris adalah bahasa asing. Motivasi untuk belajar bahasa Inggris sangat penting sehingga siswa tahu bahwa mata pelajaran, Bahasa Inggris, wajib disajikan di SMK karena bahasa Inggris

1. Bahasa internasional

2. Jendela dunia

3. Di Asia saja, seperti Singapore, Brunei Darusalam, Papua Nugini, Pakistan, Malaysia, Philipina, dll, mereka berbahasa Inggris kecuali Indonesia.

4. Bahasa Inggris wajib dikuasai Siswa SMK karena Bahasa Inggris kebutuhan dasar, untuk mengembangkan diri, karier, status, dan meningkatkan pengetahuan baik dalam negeri maupun luat negeri.

Pemberian motivasi pentingnya Bahasa Inggris akan membantu siswa untuk menyukai bahasa Inggris, bersemangat dan bekerja keras dalam belajar bahasa Inggris.

\section{Tes Kemampuan Siswa dalam Bahasa Inggris}

Untuk mengetahui sejauh mana siswa kelas XII-MM 3 SMK Mahardhika dalam penguasaan bahasa Inggris khususnya Reading Comprehension, maka pengabdi member tes kemampuan menjawab pertanyaan topic, main idea, dan pertanyaan WH-Question/5 WH, I H. Tetapi, sebelum pemberian tes, pengabdi menerangkan dulu tentang topic, dan main idea sebagai berikut:

1. The subject of most writing is also called topic. The topic answers the question," what or who is about?". The topic is usually just a word or a phrase.

2. The main ideas is the author's most important point about the topic. The main idea is usually stated in the first sentence of a paragraph. Main idea is also stated in the second sentence, middle sentence, or last sentence, even main idea is not stated.

3. Tes kemampuan siswa dalam Bahasa Inggris khususnya Reading Comprehension diambil dari Buku bahasa Inggris 
XII, karena pengajaran bahasa Inggris dilaksanakan di kelas XII yang tidak mempunyai LCD. Pengabdi sebenarnya menghendaki tes ini disambungkan dilayar. Berikut text tes kemampuan siswa dalam Reading Comprehension.

Tes kemampuan siswa dalam reading comprehension ini dilaksanakan di kelas XII MM- 3. Siswa harus duduk di kursinya masing-masing. Tetapi, yang terjadi, siswa duduk bergerombol untuk mengerjakan soal. Beberapa siswa jalan jalan untuk menyontek. Keadaan kelas tidak disiplin. Pengabdi memeriksa hasil Tes dan hasilnya;

1. Beberapa siswa tidak mengerjakan seluruh pertanyaan

2. Seluruh siswa menjawab pertanyaan dengan jawaban pendek. Dalam Jawaban Reading ada jawaban panjang sesuai dengan pola kalimat. Tetapi siswa menjawab dengan jawaban pendek.

3. Siswa kelas XII-MM 3 belum mengerti topic, main idea dan menjawab WH-Question/5 WH $1 \mathrm{H}$.

Hasil dari tes awal dapat disimpulkan secara umum bahwa siswa belum bisa fokus, mandiri, disiplin dan belum bisa menjawab pertanyaan.

\section{Praktek Implementatif}

Pada pertemuan berikutnya yaitu tanggal 28 Agustus 2018, dilaksanakan di ruang Lab. Karena pada pembelajaran ini pengabdi menggunakan LCD, menampilkan materi di screen (layar). Ruang lab tidak memadai, sehingga siswa duduk bergerombol, tetapi pengabdi dibantu dengan dua mahasiswi berusaha membuat kelas dalam keadaan tetap kondusif. Pada sesi awal pembelajaran pengabdi menampilkan materi di screen Tema Tourism Industry yang terdiri dari 3 paragraph. Setelah dilanjutkan dengan aktifitas Post Reading dengan 6 pertanyaan yang memberikan kesempatan kepada siswa untuk memahami pertanyaan dan mencoba memberikan jawaban dengan deskripsi yang benar. Team pengabdi dengan mahasiswa pendamping membantu siswa dalam menggunakan kamus -terutama kamus aplikasi seluler dan secara interaktif berusaha membantu dalam kesulitan memberikan jawaban terutama dalam masalah gramatikan dan aspek-aspek yang lain.

Tahap berikutnya team melanjutkan dengan tematik Reading for the Specific Information dengan mengajukan pertanyaan: What is the main idea of the paragraph 3? Pada Pembelajaran ini, pengabdi menampilkan teks di screen (layar). Pengabdi menampilkan teks dengan Title, Paragraph dengan maksud agar siswa faham tentang judul dan paragraf/ alinea. Pengabdi memberi jawaban dari pertanyaan yang disajikan dan meminta siswa menyalin jawaban di kertas jawaban masing masing. Siswa diminta menulis jawaban dengan kata kata, kalimat dan jawaban yang benar sesuai jawaban dilayar. Kegiatan ini melatih siswa untuk terbiasa menulis bahasa Inggris. Pengabdi dibantu dua mahasiswa mendampingi siswa yang duduk bergerombol. Pengabdi dibantu dua mahasiswa memberi arahan, menjawab pertanyaan siswa satu per satu dan terus memotivasi siswa untuk menulis kata kata, kalimat dan jawaban yang benar sesuai dengan teks di layar. Hasil dari aktivitas ini adalah seluruh siswa telah menulis kata kata, kalimat dan jawaban dengan benar. Walaupun para siswa bergerombol, keadaan kelas tetap kondusif.

Pada tahap selanjutnya dilakukan pengembangan terhadap kemampuan siswa yang sudah dicapai sebelumnya. Siswa diberi materi dengan tema "The Importance of English". Dengan tema tersebut, siswa diminta mengajukan 5 pertanyaan berkaitan dengan berdasar teks analitik tersebut dengan dasar kualifikasi pertanyaan menyangkut topic, main idea, vocabularies/sinonim, antonim ataupun berbasis $5 \mathrm{~W} 1 \mathrm{H}$. Setelah siswa melaksanakan tugas tersebut, team dan pendamping berinteraksi dengan siswa untuk melihat kesalahan yang ada dan mengoreksinya. Setelah siswa mendapatkan pengetahuan yang cukup, maka diberikan materi berikutnya dengan tema "Breakfast provides many Benefits to our Health and Wellbeing". Kemudian dilanjutkan dengan proses pembahasan interaktif terhadap materi tersebut.

Tujuan dari kegiatan ini adalah siswa mampu membuat pertanyaan dengan capaian agar siswa semakin menguasai topic, main idea, WH Question. Siswa selanjutnya berusaha membuat lima pertanyaan yaitu pertanyaan topic, main idea, synonym/antonym dan pertanyaan WH lainnya. Sebagian besar siswa mampu membuat pertanyaan

Pengajaran Reading comprehension berikutnya yaitu pada tanggal 4 September 2018 dilaksanakan di kelas semula, kelas XII- MM 3. Siswa mulai disiplin duduk di kursinya masing masing. Ada 17 siswa yang masuk dan mengikuti tes pada pertemuan yang terakhir ini. Pada sesi pertama, pengabdi menerangkan kembali tentang topic, main idea dan WH Question dan menulisnya di papan tulis, karena di ruang kelas ini tidak ada LCD.

1. The subject of most writing is also called topic. The topic answers the question," what or who is about?". The topic is usually just a word or a phrase.

2. The main ideas is the author's most important point about the topic. The main idea is usually stated in the first sentence of a paragraph. Main idea is also stated in the second sentence, middle sentence, or last sentence, even main idea is not stated.

Pengabdi juga membahasnya dengan bacaan/teks sebelumnya yaitu the importance of English dan Breakfast provides many Benefits to our Health and Wellbeing. Pengabdi dan siswa berdiskusi bersama. 


\section{EVALUASI}

Pada sesi kedua pertemuan yang terakhir ini, pengabdi memberikan tes evaluasi untuk mengetahui hasil dari pengajaran kompetensi bahasa Inggris bagi siswa Kelas XII SMK Mahardhika Surabaya dan menguji apakah Tes evaluasi dan proses pembelajaran ini memberi solusi permasalahan mitra seperti yang dibahasa di bab 1. Bahan materi bacaan/teks diambil dari buku bahasa Inggris XII. Pertanyaan mencakup topic, main idea dan WH Question yang lain. Pengabdi mengetik bacaan/teks dan pertanyaan dan waktu siswa mengerjakan soal ini. Kemudian pengabdi membagi soal ini kepada siswa yang sudah duduk di kursinya masing-masing. Pengabdi minta siswa mengerjakan sendiri di kursinya masing masing sesuai dengan waktu yang tertera dalam soal dan menjawab di lembar soal yang disediakan serta memberi nama siswa.

Setelah siswa selesai mengerjakan Evaluasi Tes, diadakan sesi foto bersama. Foto sesi bersama menunjukkan bahwa pengabdian pada masyarakat berupa pengajaran kompetensi Bahasa Inggris bagi siswa kelas XII MM 3 SMK Mahardhika telah selesai, tetapi hubungan pengabdi dan siswa tetap berjalan. Bahkan pengabdi masih memberikan teori Topic dan Main Idea pada guru Bahasa Inggris siswa kelas XII-MM 3.
Pengabdi kemudian mengoreksi hasil tes evaluasi siswa dengan hasil sebagai mana dalam Tabel 1.

Tabel Hasil Tes Evaluasi dan Nilai Sikap Waktu Tes siswa yang rajin mengikuti pembelajaran dan mengikuti tes tersebut di atas menunjukkan bahwa hasil pengajaran Kompetensi Bahasa Inggris bagi siswa Kelas XII di SMK Mahardhika Surabaya katagori baik dan sikap baik. Sikap baik maksudnya adalah siswa mengerjakan soal evaluasi di kursi masing masing dan mengerjakan sendiri. Hasil pengajaran kompetensi bahasa Inggris akan direkomendasikan ke guru Bahasa Inggris untuk diteruskan dan ditingkatkan. Guru Bahasa Inggris sekaligus Humas SMK Mahardhika mengatakan bahwa tiap kelas akan dipasang LCD dalam upaya meningkatkan pembelajaran yang lebih baik.

\section{SIMPULAN}

Pengajaran kompetensi Bahasa Inggris bagi siswa Kelas XII di SMK Mahardhika Surabaya melalui tahapan tahapan. Tahap pertama adalah desain produk/buku adalah Buku Bahasa Inggris XII dengan tema 'analytical exposition' dan sub tema pengajaran Reading, topic, main idea, dan WH Question/5 WH $1 \mathrm{H}$. Tahap berikutnya adalah pelatihan yang diawali

Tabel 1. Hasil Tes Evaluasi dan Nilai Sikap Waktu Tes

\begin{tabular}{|c|c|c|c|c|}
\hline No & Nama & Nilai & Kategori & Sikap \\
\hline 1 & Cici Maulina & 76 & Baik & Baik \\
\hline 2 & Novanda Romadona & 76 & Baik & Baik \\
\hline 3 & Achmad Fauzi & 75 & Baik & Baik \\
\hline 4 & Fildza Gertavinna K & 76 & Baik & Baik \\
\hline 5 & Siti Khumaidah & 75 & Baik & Baik \\
\hline 6 & Raditya Kosliawan & 76 & Baik & Baik \\
\hline 7 & Lutfi Kushardian & 76 & Baik & Baik \\
\hline 8 & M.Irvan Darmawan & 72 & Baik & Baik \\
\hline 9 & Surya Aji Putra & 72 & Baik & Baik \\
\hline 10 & Moch.Iqbalul Amal & 75 & Baik & Baik \\
\hline 11 & Imam Faqih Asya'ari & 75 & Baik & Baik \\
\hline 12 & Fany Rachmasari & 76 & Baik & Baik \\
\hline 13 & M.Vichy Nur Huda & 75 & Baik & Baik \\
\hline 14 & Ridho Vicky R & 76 & Baik & Baik \\
\hline 15 & M.Rajif Akbar & 75 & Baik & Baik \\
\hline 16 & Dimas Nur Ardiansyah & 76 & Baik & Baik \\
\hline 17 & Umar Faruq & 72 & Baik & Baik \\
\hline
\end{tabular}


dengan memberi motivasi, menjelaskan pengertian topic dan main idea serta tes awal untuk mengetahui kemampuan Reading Comprehension siswa kelas XII- MM 3. Setelah diketahui hasilnya, tahap berikutnya adalah siswa menulis jawaban dari pertanyaan tes awal, kemudian siswa diberi dua bacaan/teks yang diambil dari buku bahasa Inggris XII. Siswa di minta membuat lima pertanyaan tentang topic, main idea, dan 5 WH Question/5 WH 1 H supaya lebih menguasai menjawab pertanyaan. Pada pertemuan berikutnya pengabdi memberi tinjauan ulang tentang topic, main idea dan WH Question. Tahap terakhir adalah evaluasi. Pada tahap ini, pengabdi member tes evaluasi. Tes Evaluasi berisi pertanyaan topic, main idea dan WH Questios/5 WH 1 H. Hasil tes menunjukkan bahwa siswa kelas XII- MM 3 bisa menjawab pertanyaan dengan hasil katagori baik. Berkenaan dengan

\section{LAMPIRAN-LAMPIRAN}

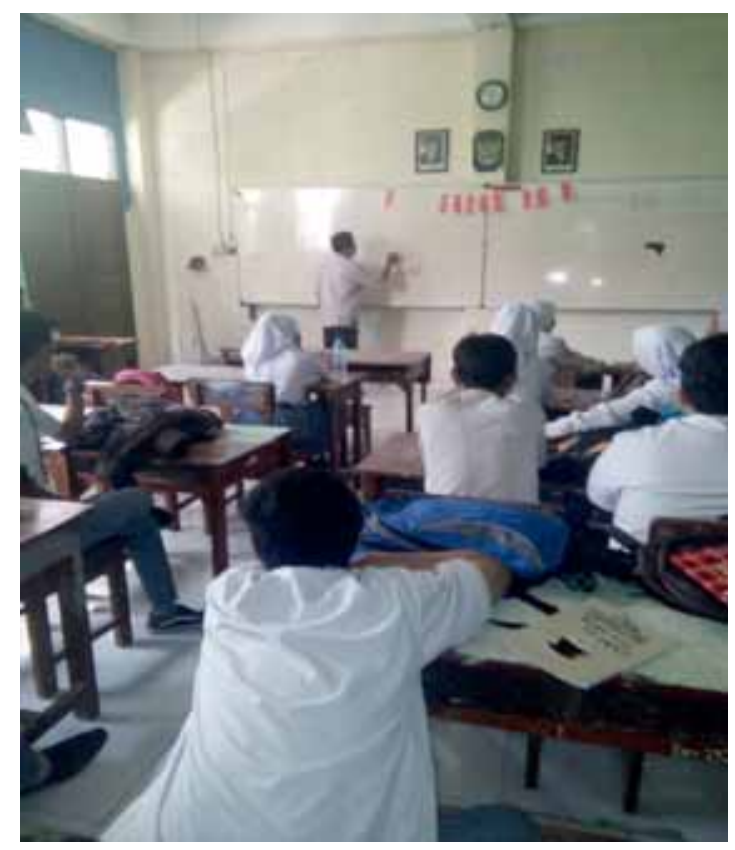

Siswa Mendengarkan pengajaran teori topic dan main idea

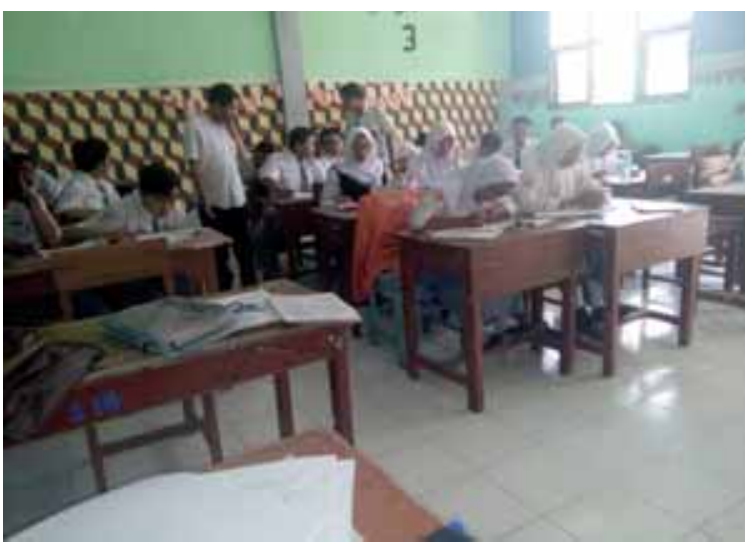

Siswa mengerjakan Ujian pra tes sikap, siswa sudah fokus, duduk di kursi masing-masing dan mandiri sehingga sikap siswa dikategorikan baik.

\section{DAFTAR PUSTAKA}

Blanchard, Karen and Christine Root. READY TO READ NOW. Longman.

Chaer, Abdul, (2003), Psikolinguistik, Kajian Teoritik, PT. RINEKA CIPTA $<$ Jakarta.

Hartley, John, (2010), Communications, Cultural and Media Studies, Jalasutra, Yogyakarta.

Rakhmat, Jalaluddin, (2007), Belajar Cerdas, Belajar Berbasis Otak, Penerbit MLC, Bandung.

http://jodenmol.wordpress.com.

htttp://pskm.kemdikbud.go.id/.

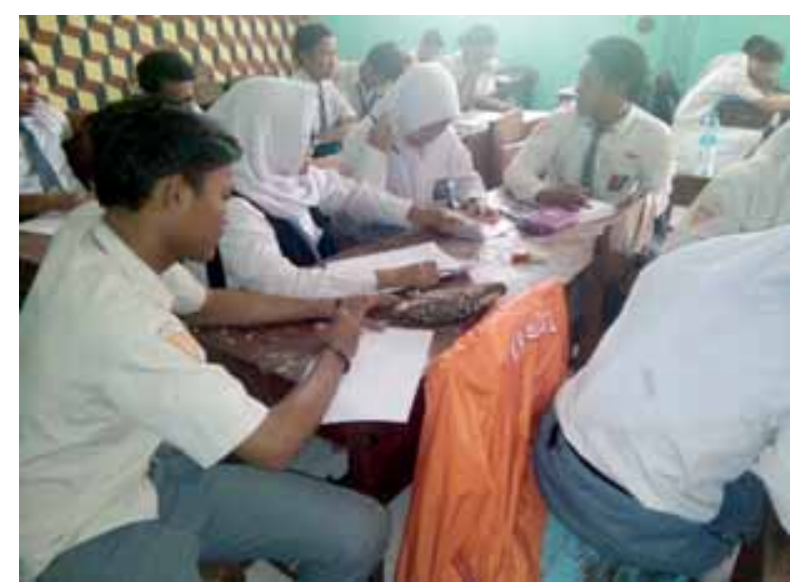

Siswa bergerombol mengikuti pelajaran di ruang lab

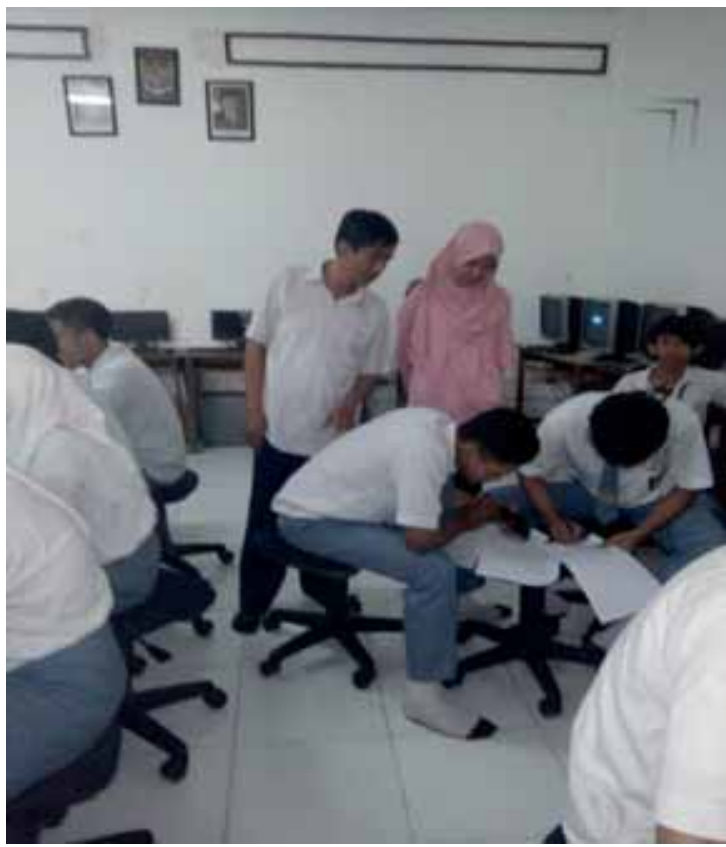

Dosen dibantu mahasiswa mendampingi siswa belajar 
Putut Handoko, dkk.: Pengajaran Kompetensi Bahasa Inggris

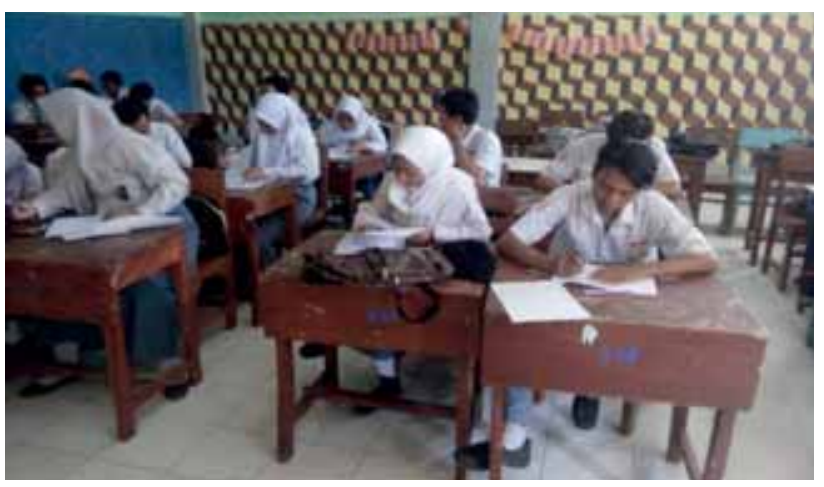

Siswa mengerjakan evaluasi tes akhir

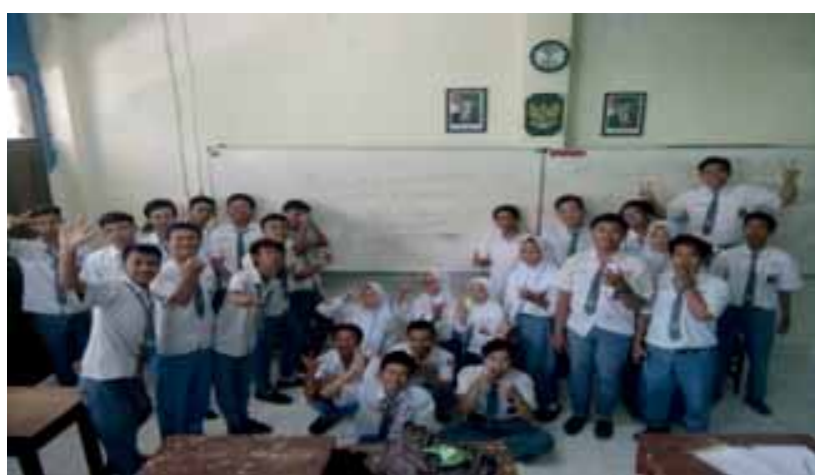

Foto bersama siswa pada akhir sesi pengajaran di SMA Mahardhika 